\title{
Hand grip strength in patients with chronic obstructive pulmonary disease
}

\author{
This article was published in the following Dove Press journal: \\ International Journal of COPD \\ 9 August 2017 \\ Number of times this article has been viewed
}

\section{Moa Jeong' \\ Hyung Koo Kang' \\ Pamela Song ${ }^{2}$ \\ Hye Kyeong Park' \\ Hoon Jung' \\ Sung-Soon Lee' \\ Hyeon-Kyoung Koo'}

'Division of Pulmonary and Critical Care Medicine, Department of Internal Medicine, ${ }^{2}$ Department of Neurology, Ilsan Paik Hospital, Inje University College of Medicine, Goyang, Republic of Korea
Correspondence: Hyeon-Kyoung Koo Division of Pulmonary and Critical Care Medicine, Department of Internal Medicine, Ilsan Paik Hospital, Inje University College of Medicine, Juhwa-ro 170, Ilsanseo-gu, Goyang

4I I-706, Republic of Korea

$\mathrm{Tel}+82319107215$

Fax +82319107219

Email gusrud9@yahoo.co.kr
Purpose: Hand grip strength (HGS) is a simple way of predicting the risk of cardiovascular disease and all-cause mortality in the general population. However, the practical significance of grip strength in patients with COPD is uncertain. The aim of this study was to compare HGS between subjects with and without COPD and to evaluate its clinical relevance in patients with COPD by using a national survey.

Methods: Data were collected from the Korean National Health and Nutrition Examination Survey. The study included 421 adults with COPD and 2,542 controls who completed questionnaires, spirometry, and a HGS test. HGS was compared between subjects with and without COPD, and the association between grip strength, lung function, and quality of life (QoL) was evaluated.

Results: The mean HGS was $33.3 \pm 9.1 \mathrm{~kg}$ in the COPD group and $29.9 \pm 9.5 \mathrm{~kg}$ in the non-COPD group; adjusted HGS was $30.9 \pm 0.33 \mathrm{~kg}$ and $30.9 \pm 0.11 \mathrm{~kg}$, respectively $(P=0.99)$. HGS was not related to forced vital capacity $(\beta=0.04, P=0.70)$ or forced expiratory volume in 1 second $(\beta=0.11, P=0.24)$ in multivariable analysis. HGS was independently associated with the EQ-5D index, but the relationship was stronger in the COPD group $(\beta=0.30, P<0.001)$ than in the nonCOPD group ( $\beta=0.21, P<0.001)$. The results were similar for each component of the EQ-5D, including mobility $(\beta=-0.25, P<0.001)$, daily activity $(\beta=-0.19, P=0.01)$, pain/discomfort $(\beta=-0.32, P<0.001)$, and anxiety/depression $(\beta=-0.16, P=0.01)$.

Conclusion: HGS was not different between subjects with and without COPD, but was associated with QoL - including mobility, daily activity, pain/discomfort, and anxiety/depression - in patients with COPD. The HGS test could be used as a marker of QoL in patients with COPD and could assist risk stratification in clinical practice.

Keywords: pulmonary disease, chronic obstructive, hand strength, respiratory function tests, quality of life, biomarker

\section{Introduction}

COPD is a complex and heterogeneous disease, characterized by chronic inflammation in the airway and lung parenchyma. ${ }^{1}$ The muscle dysfunction and exercise impairment that occurs in patients with COPD is explained by systemic inflammation arising from the lung and a decrease in the large muscle mass of the lower extremities. ${ }^{2}$ Both muscle endurance and muscle strength are indicators of muscular fitness, and reduced muscle strength - measured by hand grip strength (HGS) - has been associated with a higher risk of mortality. ${ }^{3-6}$ However, the impact of grip strength in patients with COPD is uncertain. Most of the studies that have compared grip strength between patients with COPD and controls were conducted in small numbers of participants; therefore, their results have not been consistent. Some previous studies have demonstrated decreased 
grip strength in patients with COPD, ${ }^{2,4}$ while others have not. ${ }^{7}$ Further, a recently published large cohort study reported that reduced grip strength was associated with increases in allcause mortality and incident cardiovascular disease, but not with respiratory disease, including COPD. ${ }^{5}$ The aim of this study was to identify the actual status and impact of HGS in patients with COPD by using the large body of data generated by the Korean National Health and Nutrition Examination Survey (KNHANES).

\section{Methods}

\section{Study design and participants}

KNHANES is a collection of nationally representative, crosssectional, population-based health, and nutritional surveys that have been conducted by the Korean Centers for Disease Control and Prevention (KCDC) since 1998. ${ }^{8}$ Participants were chosen by proportional allocation system sampling with multistage stratification, based on geographic area, age, and sex. KNHANES includes a health interview, physical examination, laboratory tests, and nutrition questionnaires. Spirometry was performed for subjects $>40$ years of age, and those with COPD were selected by these results. All individuals participated voluntarily and provided written informed consent. The KNHANES protocol was approved by the institutional review board of the KCDC.

\section{Measurement of variables}

Pulmonary function tests were performed in subjects aged $>40$ years according to the guidelines of the American Thoracic Society/European Respiratory Society ${ }^{9}$ using a spirometry system (model 1022; SensorMedics, Yorba Linda, CA, USA). Spirometry was repeated at least three times to ensure reproducibility and validity, and calculated on the basis of the predictive equation for the Korean population. ${ }^{10}$ The current Global Initiative for Chronic Obstructive Lung Disease (GOLD) guideline classifies patients with COPD not only by history of exacerbation but also by various symptom scores, such as the modified Medical Research Council Dyspnea Scale score or the COPD Assessment Test (CAT) score. ${ }^{1}$ KNHANES included the EuroQOL, which is a 5-item self-administered, scale-based, generic questionnaire (EQ-5D) for measurement of quality of life (QoL) in various chronic diseases such as COPD. ${ }^{11}$ As good correlations of the EQ-5D with St George's Respiratory Questionnaire (SGRQ) scores ${ }^{12,13}$ and the SGRQ with CAT scores ${ }^{14}$ had already been reported, the EQ-5D was used to represent symptom scores. The descriptive assessment includes five items: mobility, self-care, usual activities, pain/discomfort, and anxiety/depression. Each item can be used to represent profiles of health status or can be converted to a summary (EQ-5D) index. HGS was measured using a digital grip hand dynamometer (T.K.K 5401, Takei Scientific Instruments Co., Ltd., Tokyo, Japan) in a standing position with the forearm fully extended in a sideways position away from the body at the level of the thigh, resting in neutral position. Participants were asked to apply their maximum grip strength three times with both the right and left hand. A resting interval of at least 30 seconds was allowed between each measurement. HGS was defined as the average value for grip strength of the dominant hand. ${ }^{15-17}$

\section{Definitions}

COPD was defined as a spirometric result of forced expiratory volume in 1 second $\left(\mathrm{FEV}_{1}\right) /$ forced vital capacity $(\mathrm{FVC})<0.7$ in adults aged $>40$ years according to the GOLD guideline. ${ }^{1}$ The degree of airflow limitation was classified as GOLD 1 if $\mathrm{FEV}_{1}$ was $>80 \%$, GOLD 2 if $\mathrm{FEV}_{1}$ was $>50 \%$ and $\leq 80 \%$, and GOLD 3-4 if $\mathrm{FEV}_{1}$ was $\leq 50 \%$. ${ }^{1}$ Body mass index (BMI) was calculated as $\mathrm{kg} / \mathrm{m}^{2}$. Hypertension was defined as a systolic blood pressure $\geq 140 \mathrm{mmHg}$ or a diastolic blood pressure $\geq 90 \mathrm{mmHg}$, or if antihypertensive medication had been prescribed. Diabetes was defined as a fasting glucose level $\geq 126 \mathrm{mg} / \mathrm{dL}$ or hemoglobin A1c $\geq 6.5 \%$, and/or treatment for diabetes.

\section{Statistical analysis}

KNHANES was designed using a complex, stratified, multistage probability-sampling model; thus, the data were analyzed via the complex-sample design using stratification, sampling weight variables, and clustering variables to represent the Korean population using SAS version 9.3 (SAS Institute Inc., Cary, NC, USA). For between-group comparisons, the Student's $t$-test or analysis of variance was used to compare continuous variables, and the chi-square test was used to compare categorical variables. For multivariable analysis, general linear regression was used for continuous variables and logistic regression was used for categorical variables. A $P$-value $<0.05$ was considered to be statistically significant.

\section{Results}

\section{Characteristics of the participants}

Data from 2,963 adults aged $\geq 40$ years who completed questionnaire, spirometry, and the HGS test in 2015 were retrieved from KNHANES. Of these 2,963 adults, 421 met the definition of COPD; their median age was 66 (interquartile 
range 60-73) years, $317(75.3 \%)$ were male, $111(27.2 \%)$ were current smokers, $211(50.1 \%)$ were classified as GOLD $1\left(\mathrm{FEV}_{1}>80 \%\right), 196(46.6 \%)$ as GOLD $2\left(\mathrm{FEV}_{1}>50 \%\right.$ to $\leq 80 \%)$, and $14(3.3 \%)$ as GOLD $3-4\left(\mathrm{FEV}_{1} \leq 50 \%\right)$. The demographic and clinical characteristics of the non-COPD and COPD groups are summarized in Table 1. Age, sex, height, BMI, waist circumference (WC), and smoking status were significantly different between the non-COPD and COPD groups, and the prevalence rates for hypertension, diabetes, and myocardial infarction (MI)/angina were much higher in the COPD group.

\section{Hand grip strength in COPD}

In the general population, HGS was significantly associated with FVC $(\mathrm{R}=0.76, P<0.001)$ and $\mathrm{FEV}_{1}(\mathrm{R}=0.69, P<0.001)$, but not with the FVC \% predicted ( $\mathrm{R}=0.09, P=0.08)$ or $\mathrm{FEV}_{1} \%$ predicted $(\mathrm{R}=0.04, P=0.43$; Figure 1$)$. After adjustment for age, sex, and height, HGS was not related to either FVC $(\beta=0.04, P=0.70)$ or $\mathrm{FEV}_{1}(\beta=0.11, P=0.24)$ in the COPD group.

The mean HGS in the COPD group was $33.3 \pm 9.1 \mathrm{~kg}$ and that in the non-COPD group was $29.9 \pm 9.5 \mathrm{~kg}$ (Table 1).

Table I Baseline characteristics of study participants

\begin{tabular}{|c|c|c|c|}
\hline & $\begin{array}{l}\text { Non-COPD } \\
(\mathrm{N}=\mathbf{2 , 5 4 2 )}\end{array}$ & $\begin{array}{l}\text { COPD } \\
(\mathrm{N}=421)\end{array}$ & $P$-value \\
\hline Age & $56.4 \pm 10.3$ & $65.4 \pm 8.8$ & $<0.00$ I \\
\hline Male sex & $992(39.0)$ & $317(75.3)$ & $<0.00$ I \\
\hline Height, cm & $160.9 \pm 8.7$ & $164.5 \pm 8.6$ & $<0.00 \mathrm{I}$ \\
\hline $\mathrm{BMI}, \mathrm{kg} / \mathrm{m}^{2}$ & $24.3 \pm 3.1$ & $23.9 \pm 2.8$ & 0.01 \\
\hline Current smoker & $344(13.7)$ & III (27.2) & $<0.001$ \\
\hline Waist circumference, $\mathrm{cm}$ & $83.5 \pm 8.9$ & $86.1 \pm 8.3$ & $<0.00 \mathrm{I}$ \\
\hline Hypertension & $722(28.4)$ & $172(40.9)$ & $<0.00$ I \\
\hline Diabetes & $246(9.7)$ & $68(16.2)$ & $<0.00$ I \\
\hline Ml/angina & $73(3.0)$ & $22(5.4)$ & 0.01 \\
\hline Depression & $139(5.5)$ & $15(3.6)$ & 0.16 \\
\hline \multicolumn{4}{|l|}{ Pulmonary function test } \\
\hline FVC, L & $3.45 \pm 0.84$ & $3.68 \pm 0.91$ & $<0.001$ \\
\hline FVC, \% predicted & $93.3 \pm 11.2$ & $91.1 \pm 14.2$ & 0.002 \\
\hline $\mathrm{FEV}_{1}, \mathrm{~L}$ & $2.73 \pm 0.66$ & $2.35 \pm 0.64$ & $<0.001$ \\
\hline $\mathrm{FEV}_{1}, \%$ predicted & $94.9 \pm 11.6$ & $79.9 \pm 15.3$ & $<0.001$ \\
\hline $\mathrm{FEV}_{1} / \mathrm{FVC}, \%$ & $79.4 \pm 4.7$ & $63.9 \pm 6.3$ & $<0.001$ \\
\hline Hand grip strength, kg & $29.9 \pm 9.5$ & $33.3 \pm 9.1$ & $<0.00 \mathrm{I}$ \\
\hline EQ-5D index & $0.94 \pm 0.11$ & $0.92 \pm 0.13$ & $<0.001$ \\
\hline Mobility & $1.49 \pm 1.65$ & $1.5 \mathrm{I} \pm \mathrm{I} .46$ & 0.77 \\
\hline Self-care & $1.38 \pm 1.64$ & $1.33 \pm 1.45$ & 0.53 \\
\hline Daily activity & $1.43 \pm 1.64$ & $1.39 \pm 1.45$ & 0.64 \\
\hline Pain/discomfort & $1.61 \pm 1.66$ & $1.58 \pm 1.47$ & 0.71 \\
\hline Anxiety/depression & $1.46 \pm 1.65$ & $1.38 \pm 1.46$ & 0.36 \\
\hline
\end{tabular}

Note: Data shown as mean \pm standard deviation and $\mathrm{n}(\%)$.

Abbreviations: BMI, body mass index; $\mathrm{MI}$, myocardial infarction; FVC, forced vital capacity; FEV, forced expiratory volume in I second; EQ-5D, EuroQOL 5-item questionnaire.
The COPD group included more men and the mean HGS was significant higher in men than in women $(37.2 \pm 9.2 \mathrm{vs}$ 23.1 $\pm 5.2, P<0.001)$; therefore, HGS was compared between the groups again after stratification by sex. Mean HGS was $39.0 \pm 7.2,36.5 \pm 7.3,23.8 \pm 4.7$, and $22.1 \pm 5.0$, respectively, in the men without COPD, men with COPD, women without COPD, and women with COPD. There was no interaction between COPD and sex in relation to HGS $(P=0.31)$. The sex-adjusted HGS in the non-COPD group was $31.4 \pm 0.1$ and that in the COPD group was $29.3 \pm 0.4$ (mean difference $2.1 \pm 0.4 ; P<0.001)$. Because HGS was related to age $(\mathrm{R}=-0.41, P<0.001)$ and height $(\mathrm{R}=0.67, P<0.001)$, multivariable analysis was performed with adjustment for age, sex, and height. There was no statistically significant difference in adjusted HGS between the non-COPD group and the COPD group $(30.9 \pm 0.11$ vs $30.9 \pm 0.33$; mean difference $0.005 \pm 0.345 ; P=0.99)$. The values of HGS according to age group and sex are summarized in Table 2 . After further adjustment by BMI (R=0.21, $P<0.001)$, WC ( $\mathrm{R}=0.26, P<0.002)$, presence of $\mathrm{MI} /$ angina $(30.3 \pm 10.0$ vs $27.7 \pm 9.8, P=0.003)$, hypertension $(30.2 \pm 9.7$ vs $27.9 \pm 9.5$, $P<0.001)$, and diabetes $(29.6 \pm 9.7$ vs $27.7 \pm 9.7, P<0.001)-$ in addition to age, sex, and height - the adjusted HGS was even higher in the COPD group (31.8 \pm 0.7$)$ when compared with the non-COPD group $(29.7 \pm 0.5 ; P=0.01)$.

Among the patients with COPD, HGS was investigated according to the degree of airflow limitation. The mean HGS was 30.4 \pm 9.5 in GOLD 1, 30.6 \pm 9.3 in GOLD 2, and $29.8 \pm 11.5$ in GOLD $3-4(P=0.93)$. In multivariable analysis, the HGS adjusted by age, sex, and height was $31.1 \pm 0.11$ in GOLD 1, 29.9 \pm 0.3 in GOLD 2, and 29.6 \pm 1.5 in GOLD 3-4 $(P<0.001$ between GOLD 1 and GOLD 2 groups). However, after additional adjustment of BMI, WC, presence of MI/ angina, hypertension, and diabetes in the model, the adjusted HGS was $29.6 \pm 0.5,29.7 \pm 0.7$, and $30.6 \pm 1.5$, respectively, which was not significantly different $(P=0.80)$.

\section{Hand grip strength and QoL}

The EQ-5D index was poorer in adults with COPD than in those without COPD $(0.94 \pm 0.11$ vs $0.92 \pm 0.13, P<0.001$; Table 1). There was no statistically significant difference in any of the components of the EQ-5D, including mobility, self-care, daily activity, pain/discomfort, and anxiety/ depression, between the non-COPD and COPD groups (Table 1). In the COPD group, the EQ-5D index was related to age $(\mathrm{R}=-0.32, P<0.001), \mathrm{BMI}(\mathrm{R}=-0.07, P<0.001)$, WC ( $\mathrm{R}=-0.11, P<0.001)$, presence of $\mathrm{MI} /$ angina $(0.94 \pm 0.11$ vs $0.84 \pm 0.20, P<0.001)$, hypertension $(0.93 \pm 0.11$ vs $0.90 \pm 0.15$, 

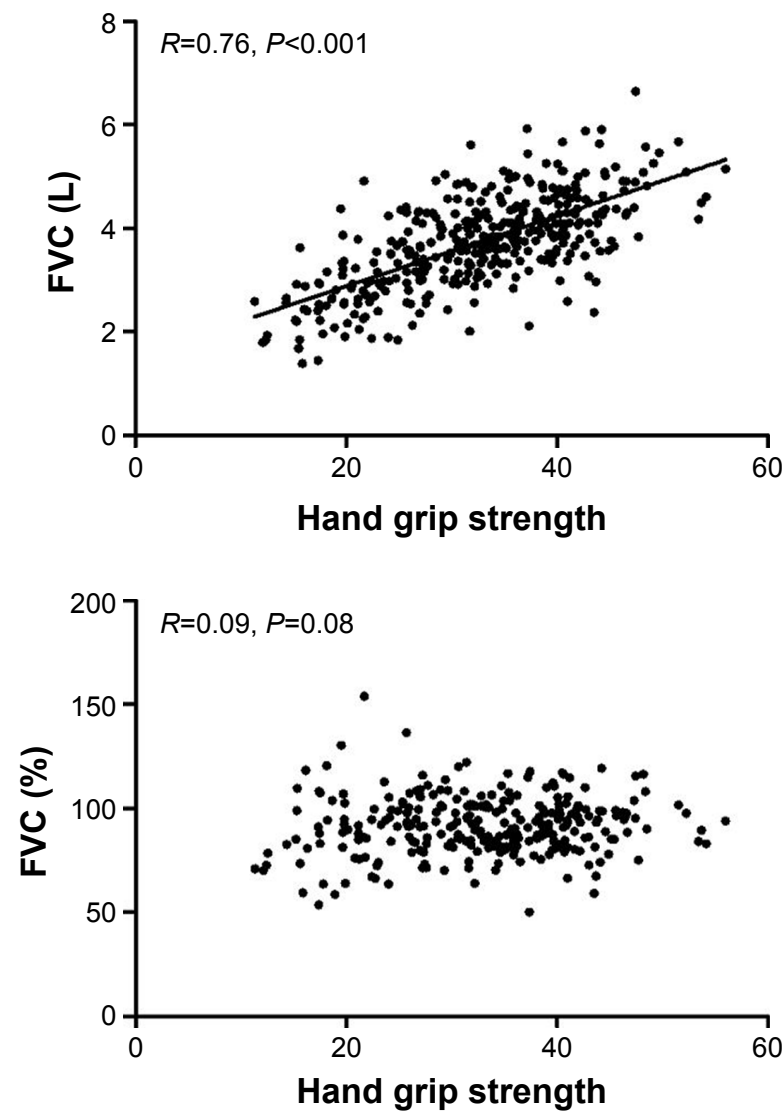

Figure I Relationship between hand grip strength and pulmonary function.

Abbreviations: FVC, forced vital capacity; $\mathrm{FEV}_{1}$, forced expiratory volume in I second.
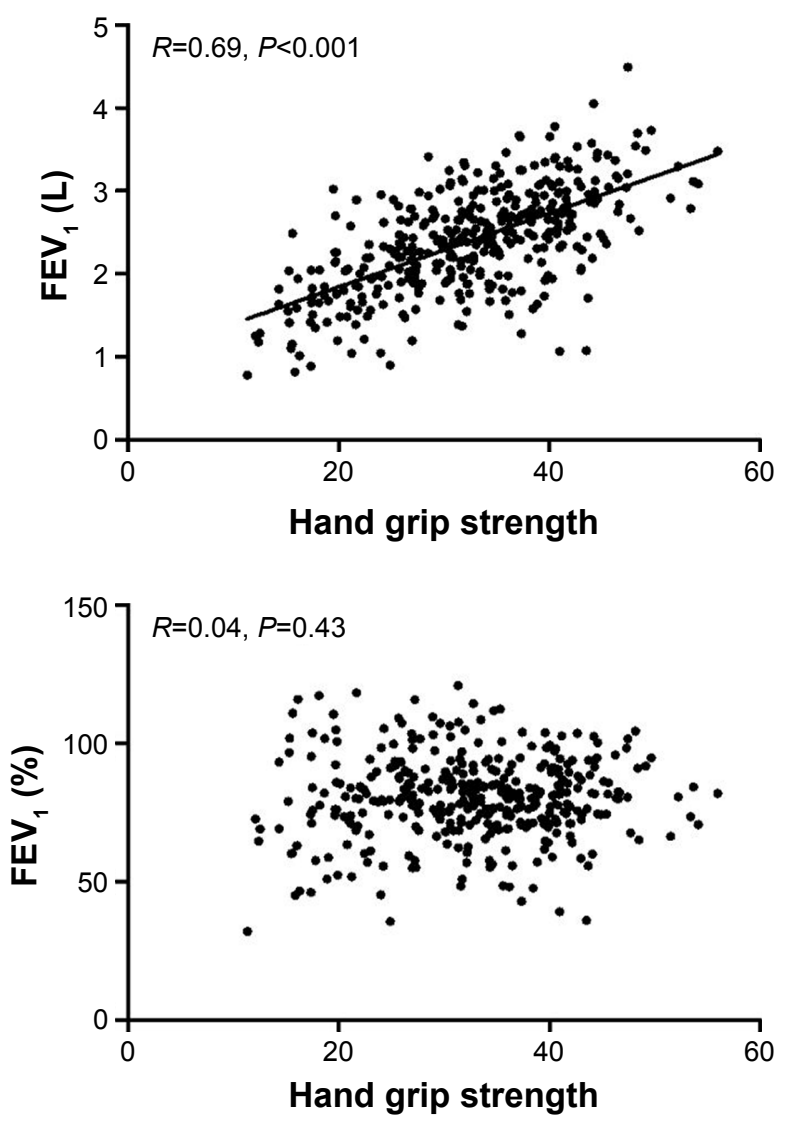

$P=0.03)$, and depression $(0.94 \pm 0.11$ vs $0.84 \pm 0.19, P<0.001)$. In multivariable analysis for the association between EQ-5D index and HGS, we adjusted age, sex, BMI, WC, FEV (\% predicted), presence of $\mathrm{MI} /$ angina, hypertension, and depression, and sex and BMI were extracted by a backward elimination method. The HGS was independently associated with the EQ-5D index, but showed an even stronger relationship in the COPD group $(\beta=0.30, P<0.001)$ than in the non-COPD group $(\beta=0.21, P<0.001)$. This relationship was significant for all components of the EuroQOL except for self-care (Table 3).

Table 2 Hand grip strength stratified by age and sex

\begin{tabular}{lllll}
\hline & Age group & Non-COPD & COPD & P-values \\
\hline Male & $40-50$ & $43 . I \pm 6.9$ & $43 . I \pm 7.4$ & $>0.99$ \\
& $5 I-60$ & $39.2 \pm 6 . I$ & $4 I .0 \pm 7.0$ & 0.04 \\
& $6 I-70$ & $36.3 \pm 6 . I$ & $36.4 \pm 6.2$ & 0.95 \\
\multirow{6}{*}{ Female } & $7 I-80$ & $32.0 \pm 5.5$ & $32.6 \pm 6.0$ & 0.45 \\
& $40-50$ & $25.7 \pm 4.4$ & $22.6 \pm 4.9$ & 0.33 \\
& $5 I-60$ & $24.4 \pm 4.2$ & $24.7 \pm 5 . I$ & 0.77 \\
& $6 I-70$ & $23.1 \pm 4.4$ & $22.6 \pm 4.2$ & 0.44 \\
& $7 I-80$ & $19.6 \pm 4.3$ & $20.3 \pm 5.4$ & 0.46 \\
\hline
\end{tabular}

Note: Data shown as mean \pm standard deviation.

\section{Discussion}

In our national survey, HGS was not significantly different between adults with and without COPD and was not associated with degree of airflow limitation. However, grip strength had a stronger association with QoL - including mobility, daily activity, pain/discomfort, and anxiety/depression - in adults with COPD than in those without COPD.

Numerous studies have shown that exercise capacity is associated with mortality, exacerbations, and health-related

Table 3 Multivariable analysis for association between quality of life and hand grip strength

\begin{tabular}{llllll}
\hline Adjusted EuroQOL & \multicolumn{2}{l}{ Non-COPD } & & \multicolumn{2}{c}{ COPD } \\
\cline { 2 - 3 } \cline { 5 - 6 } \cline { 5 - 6 } & $\boldsymbol{\beta}$ & $\boldsymbol{P}$-values & & $\beta$ & \multicolumn{1}{c}{$\boldsymbol{P}$-values } \\
\hline Total & 0.21 & $<0.001$ & & 0.30 & $<0.001$ \\
Mobility & -0.14 & $<0.001$ & & -0.25 & $<0.001$ \\
Self-care & -0.01 & 0.78 & & -0.06 & 0.32 \\
Daily activity & -0.09 & $<0.001$ & & -0.19 & 0.01 \\
Pain/discomfort & -0.15 & $<0.001$ & & -0.32 & $<0.001$ \\
Anxiety/depression & -0.08 & 0.002 & & -0.16 & 0.01 \\
\hline
\end{tabular}

Note: Adjusted by age, waist circumference, FEV (\% predicted), presence of myocardial infarction/angina, hypertension, and depression in addition to hand grip strength. 
QoL in patients with COPD; therefore, the 6-minute walk distance has been included in the BODE index (Body mass index, airflow Obstruction, Dyspnea and Exercise capacity). ${ }^{18-22}$ However, in spite of its importance, exercise capacity is rarely measured in clinical practice because it entails a certain amount of time and space as well as a degree of risk, or cannot be performed because of comorbidities, such as arthritis or stroke. Therefore, much effort has been made to find a simpler way of measuring exercise capacity than the 6-minute walk test, and the HGS test is one of the proposed alternatives. The HGS test has been demonstrated to have an association with mortality in the general population, ${ }^{5}$ and this relationship has also been shown to be valid in patients with COPD. ${ }^{3,4,6}$ However, the relationship between HGS and the 6-minute walk distance or other outcomes of COPD has not yet been clarified. Therefore, the aim of this study was to ascertain the clinical impact of HGS in patients with COPD using a national survey. Reduction of HGS in COPD has been reported previously, but the relevant studies were conducted in small numbers of subjects or yielded inconsistent results. Felipe et al reported reduced HGS in 27 patients with COPD when compared with 12 healthy subjects, ${ }^{4}$ and Gosselink et al described a similar result in 40 patients with COPD and 22 healthy elderly subjects. ${ }^{2}$ However, Calik-Kutukcu et al could not replicate this finding in their study of 20 patients with COPD and 20 controls. $^{7}$ Puhan et al measured HGS in 409 patients with COPD without a control group, but HGS did not tend to worsen with increasing airflow limitation and was not related to exacerbations. ${ }^{3}$ Recently, the PURE study found no association between HGS and incidental respiratory disease including COPD. ${ }^{5}$ Therefore, a study was needed to clarify the actual status of HGS and its clinical roles in patients with COPD.

Our study compared HGS between a COPD group and a control group using a large dataset from a national survey, and found that HGS was neither decreased in adults with COPD nor related to the severity of airflow limitation. The crude values of HGS were considerably higher in COPD group. However, because the COPD group included more elderly men, a multivariable analysis adjustment for age, sex, and height was performed, and there was no significant difference in HGS. On the contrary, a reduction of HGS was associated with poorer health-related QoL - not only in terms of mobility and daily activities, but also with regard to pain, discomfort, anxiety, and depression. HGS can be used as a biomarker of a patient's overall QoL independent of lung function. In our study, this relationship was more relevant in adults with COPD than in control subjects. Given that the current
GOLD guideline emphasizes history of exacerbation and QoL to a greater degree than airflow limitation, ${ }^{1}$ measurement of QoL is a very important factor when stratifying risk and predicting the prognosis. However, it is difficult to determine overall QoL in all patients during their brief appointments in the outpatient clinic. Our study highlights the importance of assessing HGS, which is a simple and inexpensive method for estimation of general QoL in patients with COPD.

This study has several potential limitations. First, it was a cross-sectional study that drew data from a national survey; therefore, we could not assess longitudinal changes in HGS or test for an association between HGS and exacerbation or mortality. We could not obtain data for other measurements of exercise capacity, such as the 6-minute walk distance; thus, we could not analyze the correlation between HGS and 6-minute walk distance. Second, we used the EuroQOL instead of the CAT score to measure QoL. The EuroQOL is a generic questionnaire, although it had been reported to have a good correlation with the SGRQ score. ${ }^{12,13}$ Third, there were no data available for diffusing capacity for carbon monoxide or the emphysema index; therefore, we could not identify their association with HGS. Fourth, because this study was part of a national health survey, we could not evaluate postbronchodilator $\mathrm{FEV}_{1}$ and $\mathrm{FVC}$, which are commonly used as lung function parameters in patients with COPD. Fifth, the number of patients with advanced COPD in our study was smaller than that of those with COPD 1-2. Although this proportion reflects the actual prevalence of COPD in the general population, caution should be exercised in interpreting our findings. Sixth, although we measured HGS according to manufacturer's instructions, it has been reported that varying the position of the forearm, ${ }^{23}$ elbow, ${ }^{24-26}$ or shoulder ${ }^{27}$ could alter the values of grip strength. However, other studies have reported no differences when the measurements are taken from the dominant hand, ${ }^{26}$ or in different position, such as sitting or standing. ${ }^{28}$ Further longitudinal studies evaluating the benefit of HGS in clinical practice using standardized protocol are required to confirm the results of our study.

\section{Conclusion}

Although HGS is not related to the presence or severity of airflow limitation, it could be used as a biomarker of general QoL to risk-stratify patients with COPD. Further studies of the natural course of HGS and the response to treatment are needed.

\section{Disclosure}

The authors report no conflicts of interest in this work. 


\section{References}

1. Global Initiative for Chronic Obstructive Lung Disease (GOLD). Global Strategy for the Diagnosis, Management and Prevention of COPD. http://goldcopd.org/download/326/. Accessed March 1, 2017.

2. Gosselink R, Troosters T, Decramer M. Distribution of muscle weakness in patients with stable chronic obstructive pulmonary disease. J Cardiopulm Rehabil. 2000;20(6):353-360.

3. Puhan MA, Siebeling L, Zoller M, Muggensturm P, Ter Riet G. Simple functional performance tests and mortality in COPD. Eur Respir J. 2013;42(4):956-963.

4. Felipe C, Bartolome C, Miguel D, Victor PP. Longitudinal changes in handgrip strength, hyperinflation, and 6-minute walk distance in patients with COPD and a control group. Chest. 2015;148(4):986-994.

5. Leong DP, Teo KK, Rangarajan S, et al; Prospective Urban Rural Epidemiology (PURE) Study investigators. Prognostic value of grip strength: findings from the Prospective Urban Rural Epidemiology (PURE) study. Lancet. 2015;386(9990):266-273.

6. Burtin C, Ter Riet G, Puhan MA, et al. Handgrip weakness and mortality risk in COPD: a multicentre analysis. Thorax. 2016;71(1):86-87.

7. Calik-Kutukcu E, Savci S, Saglam M, et al. A comparison of muscle strength and endurance, exercise capacity, fatigue perception and quality of life in patients with chronic obstructive pulmonary disease and healthy subjects: a cross-sectional study. BMC Pulm Med. 2014;14:6.

8. National Health and Nutrition Examination Survey Report 2014. Ministry of Health and Welfare, Seoul, South Korea (in Korean). Available from: https://knhanes.cdc.go.kr/knhanes/index.do. Accessed January 10, 2017.

9. American Thoracic Society. Standardization of spirometry, 1994 update. Am J Respir Crit Care Med. 1995;152(3):1107-1136.

10. Choi JK, Paek DM, Lee JO. Normal predictive values of spirometry in Korean population. Tuberc Respir Dis. 2005;58:230-242.

11. EuroQol Group. EuroQol - a new facility for measurement of health related quality of life. Health Policy. 1990;16:199-208.

12. Wilke S, Janssen DJ, Wouters EF, Schols JM, Franssen FM, Spruit MA. Correlations between disease-specific and generic health status questionnaires in patients with advanced COPD: a one-year observational study. Health Qual Life Outcomes. 2012;10:98.

13. Rutten-van Mölken MP, Oostenbrink JB, Tashkin DP, Burkhart D, Monz BU. Does quality of life of COPD patients as measured by the generic EuroQol five-dimension questionnaire differentiate between COPD severity stages? Chest. 2006;130(4):1117-1128.

14. Canavan JL, Dilaver D, Clark AL, et al. Clinical COPD Questionnaire in patients with chronic respiratory disease. Respirology. 2014; 19(7):1006-1012.
15. Roberts HC, Denison HJ, Martin HJ, et al. A review of the measurement of grip strength in clinical and epidemiological studies: towards a standardised approach. Age Ageing. 2011;40(4):423-429.

16. Yu R, Ong S, Cheung O, Leung J, Woo J. Reference values of grip strength, prevalence of low grip strength, and factors affecting grip strength values in chinese adults. J Am Med Dir Assoc. 2017;18(6):551.

17. Yoo JI, Choi H, Ha YC. Mean hand grip strength and cut-off value for sarcopenia in Korean adults using KNHANES VI. J Korean Med Sci. 2017;32(5):868-872.

18. Pinto-Plata VM, Cote C, Cabral H, Taylor J, Celli BR. The 6-min walk distance: change over time and value as a predictor of survival in severe COPD. Eur Respir J. 2004;23(1):28-33.

19. Marquis K, Debigare R, Lacasse Y, et al. Midthigh muscle crosssectional area is a better predictor of mortality than body mass index in patients with chronic obstructive pulmonary disease. Am J Respir Crit Care Med. 2002;166(6):809-813.

20. Celli BR, Cote CG, Marin JM, et al. The body-mass index, airflow obstruction, dyspnea, and exercise capacity index in chronic obstructive pulmonary disease. $N$ Engl J Med. 2004;350:1005-1012.

21. Puhan MA, Garcia-Aymerich J, Frey M, et al. Expansion of the prognostic assessment of patients with chronic obstructive pulmonary disease: the updated BODE index and the ADO index. Lancet. 2009; 374:704-711.

22. Spruit MA, Polkey MI, Celli B, et al; Evaluation of COPD Longitudinally to Identify Predictive Surrogate Endpoints (ECLIPSE) study investigators. Predicting outcomes from 6-minute walk distance in chronic obstructive pulmonary disease. J Am Med Dir Assoc. 2012; 13(3):291-297.

23. Richards LG, Olson B, Palmiter-Thomas P. How forearm position affects grip strength. Am J Occup Ther. 1996;50(2):133-138.

24. Mathiowetz V, Rennells C, Donahoe L. Effect of elbow position on grip and key pinch strength. J Hand Surg Am. 1985;10(5):694-697.

25. Su CY, Lin JH, Chien TH, Cheng KF, Sung YT. Grip strength: relationship to shoulder position in normal subjects. Gaoxiong Yi Xue Ke Xue Za Zhi. 1993;9(7):385-391.

26. Desrosiers J, Bravo G, Hébert R, Mercier L. Impact of elbow position on grip strength of elderly men. J Hand Ther. 1995;8(1):27-30.

27. Su CY, Lin JH, Chien TH, Cheng KF, Sung YT. Grip strength in different positions of elbow and shoulder. Arch Phys Med Rehabil. 1994;75(7):812-815.

28. Shechtman O, MacKinnon L, Locklear C. Using the BTE Primus to measure grip and wrist flexion strength in physically active wheelchair users: an exploratory study. Am J Occup Ther. 2001;55(4):393-400.
International Journal of COPD

\section{Publish your work in this journal}

The International Journal of COPD is an international, peer-reviewed journal of therapeutics and pharmacology focusing on concise rapid reporting of clinical studies and reviews in COPD. Special focus is given to the pathophysiological processes underlying the disease, intervention programs, patient focused education, and self management protocols.
Dovepress

This journal is indexed on PubMed Central, MedLine and CAS. The manuscript management system is completely online and includes a very quick and fair peer-review system, which is all easy to use. Visit $\mathrm{http}: / / \mathrm{www}$. dovepress.com/testimonials.php to read real quotes from published authors. 